\title{
Lung transplantation for pulmonary hypertension
}

\author{
M. Patricia George, Hunter C. Champion, and Joseph M. Pilewski \\ Department of Medicine, University of Pittsburgh, Pittsburgh, Pennsylvania
}

\begin{abstract}
Although medical therapies for pulmonary arterial hypertension have greatly improved, it remains a chronic and fatal disease. For patients who are refractory to medical therapy, lung transplantation is an important treatment option. This review discusses issues pertaining to indications for transplant, preparation for transplant and listing, operative issues, and outcomes for patients with pulmonary arterial hypertension.
\end{abstract}

Key Words: surgical treatment, lung transplant, outcome, pulmonary arterial hypertension

\section{INTRODUCTION}

Pulmonary arterial hypertension (PAH), initially described hemodynamically in 1951 by David Dresdale, was a disease that for decades had no effective treatment. ${ }^{[1]}$ Prior to the transplant era, the chances for survival with pulmonary hypertension were grim, with median survival only 2.8 years. ${ }^{[2]}$ However, two early discoveries changed the prognosis for patients with pulmonary arterial hypertension: lung transplantation and the discovery of epoprostenol. Heart-lung transplantation developed as a surgical means to treat pulmonary vascular disease, and the first heart-lung transplant, was performed at Stanford by Norman Shumway, John Wallwork, and Bruce Reitz in 1981. [3] Soon after the first successful heart-lung transplants, single and bilateral lung transplantation evolved. ${ }^{[4-6]}$ Joel Cooper reported the first single lung transplant in a patient with pulmonary fibrosis in 1986, and soon the bilateral sequential lung transplant technique became favored. ${ }^{[4-6]}$ With early surgical successes, the number of lung transplants registered per year worldwide continues to grow, surpassing 2700 transplants in 2009 (Fig. 1). ${ }^{[7]}$

This early success in surgical treatment of PAH was soon followed by the major medical discovery of prostacyclin

\footnotetext{
Address correspondence to:

M. Patricia George, MD

Division of Pulmonary, Allergy, and Critical Care Medicine

University of Pittsburgh, 628 NW MUH

3459 Fifth Avenue, Pittsburgh PA 15213 USA

Phone: 412/692-2210

Fax: 412/692-2260

Email: georgemp2@upmc.edu
}

(epoprostenol) ${ }^{[8,9]}$ A landmark randomized control trial demonstrated that intravenous epoprostenol produced improved symptoms, hemodynamics, and increased survival in patients with primary (idiopathic) PAH, thereby changing the course of this disease. ${ }^{[10,11]}$ In a randomized controlled trial, epoprostenol was also associated with a 5-year survival of 55\%. ${ }^{[12]}$ Since this medical breakthrough, there have been many more discoveries, with the development of new prostacyclin analogs (treprostinil, iloprost) as well as development of other classes of medications. ${ }^{[13-16]}$ These include endothelin receptor antagonists (bosentan, ambrisentan ${ }^{[17,18]}$ phosphodiesterase-5 (PDE5) inhibitors (sildenafil, tadalafil), ${ }^{[19]}$ and newer agents currently under study (imatinib, riociguat). ${ }^{[20,21]}$ These medications have been shown to improve hemodynamics, symptoms, exercise capacity, time to clinical worsening, and quality of life in patients with idiopathic $\mathrm{PAH}$. A recent meta-analysis combined clinical trials of goal-oriented $\mathrm{PAH}$ therapy, and showed that active treatment was associated with an overall reduction in mortality of $43 \%(\mathrm{P}=0.048) .{ }^{[22]}$

The past 30 years have been notable for parallel developments in surgical and medical therapies for pulmonary hypertension (Fig. 2). Although successful

\begin{tabular}{|l|l|}
\hline \multicolumn{2}{|c|}{ Access this article online } \\
\hline Qulck Response Code: & Website: www.pulmonarycirculation.org \\
\hline & DOI: 10.4103/2045-8932.83455 \\
\cline { 2 - 2 } & \\
& How to cite this article: George MP, \\
& Champion HC, Pilewski JM. Lung \\
& transplantation for pulmonary hypertension. \\
& Pulm Circ 2011;1:182-91.
\end{tabular}


developments in the medical treatment of patients with $\mathrm{PAH}$ has decreased the number of patients listed for lung transplantation, there remain patients who are refractory to, or progress despite multidrug therapy. For this population, lung transplantation often remains the only viable option for improving survival. This review article will address the indications for lung transplant in $\mathrm{PAH}$, specific operative considerations unique to patients with PAH, and transplant outcomes in patients with PAH, both in terms of postoperative physiologic changes and survival.

\section{Definitions and nomenclature in PAH}

PAH is defined by a mean pulmonary artery pressure greater than $25 \mathrm{mmHg}$ at rest and a normal pulmonary capillary wedge pressure of $15 \mathrm{mmHg}$ or less with a pulmonary vascular resistance greater than 3 Wood units. ${ }^{[23]}$ As treatments have developed for PAH, so has our understanding and classification system. The initial classification scheme in 1973 involved only two categories: primary and secondary PAH. ${ }^{[1,24]}$ This was expanded into 5 major categories at the Second World Symposium

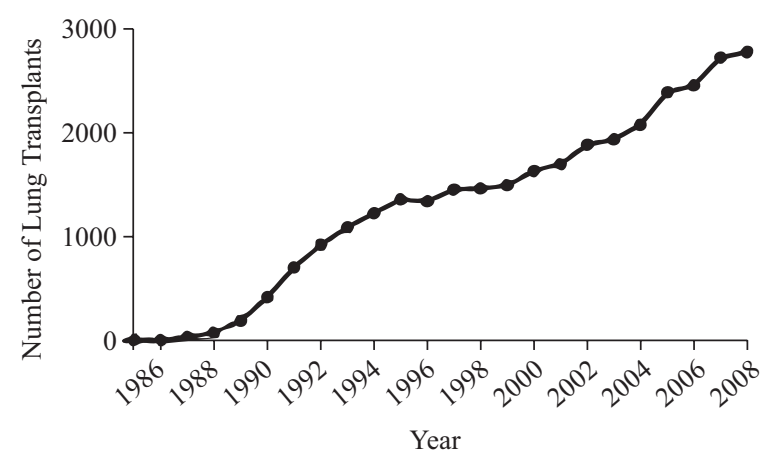

Figure 1: Since the first lung transplant in 1986, the number of lung transplants continues to grow. ${ }^{[7]}$ on PAH in Evian, France in 1998. Categorization into groups based on putative similar pathophysiology helped investigators to conduct clinical trials, and led to the approval of 8 medicines for PAH. ${ }^{[24]}$ In 2003 at the Third World Symposium on PAH in Venice, Italy, the terms primary and secondary PAH were eliminated, although some people still use these terms today. ${ }^{[25]}$ Finally in 2008 the Fourth World Symposium of PAH at Dana Point, California, the nomenclature was further revised to better group similar diseases and account for mutations, and continues to be the nomenclature in use today (Table 1). ${ }^{[24]}$ Lung transplantation has been performed commonly for patients in diagnostic groups 1,3, and 5 . Patients with idiopathic pulmonary arterial hypertension (IPAH) comprise $3.3 \%$ of all transplant recipients and $5.4 \%$ of double lung transplant recipients. ${ }^{[7]}$ This article will pertain mainly to patients with IPAH unless otherwise stated.

\section{INDICATIONS: REFERRAL FOR LUNG TRANSPLANT IN PAH}

Although we have made considerable progress in the medical management of PAH, not all patients respond equally well to medications. In addition, those who respond initially may suffer a sudden decline in clinical status. It is recommended that lung transplantation be utilized for patients who do not respond to optimal vasodilator therapy (Table 2). Sitbon and colleagues identified a high-risk subset of patients as those who 3 months following initiation of prostacyclin therapy remain in New York Heart Association functional class III or IV or do not achieve a 30\% drop in pulmonary vascular resistance from baseline. ${ }^{[12]}$ Other risk factors associated with poor outcomes include hyponatremia,

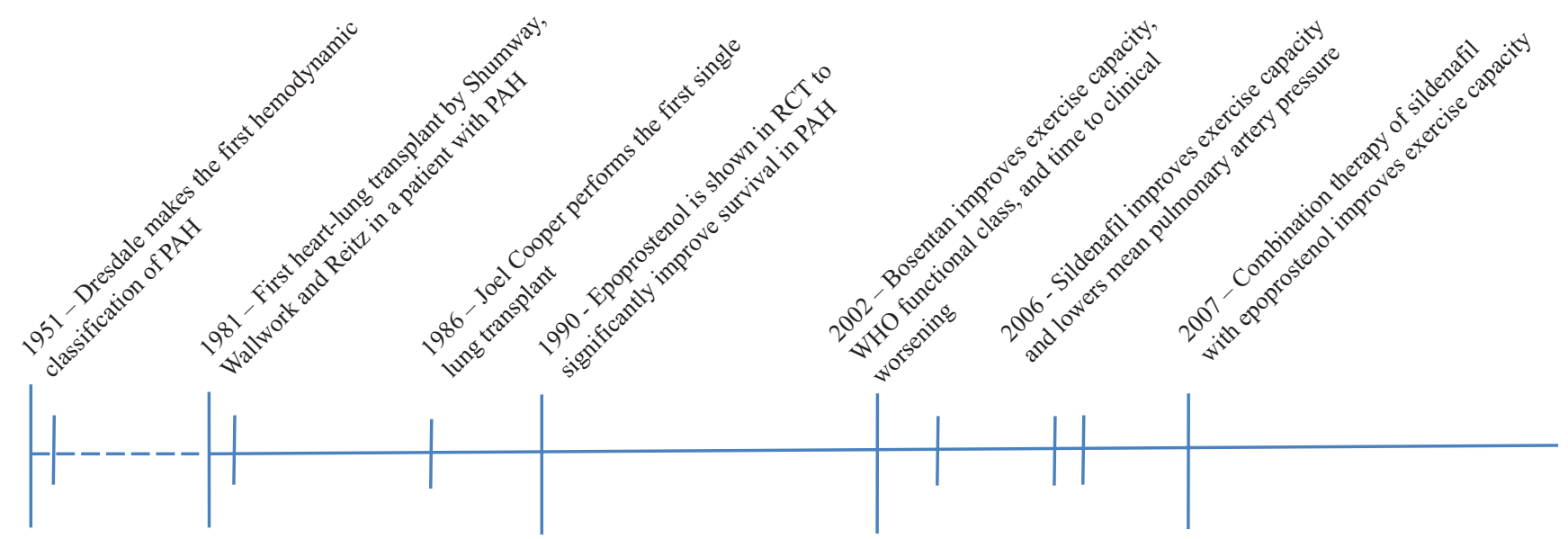

Ongoing: Trials in comination therapies Vasodilator therapy trials in APAH New agents: imatinib, riociguat

Figure 2: Timeline of major medical and surgical developments in the treatment of pulmonary arterial hypertension. 


\begin{tabular}{|c|c|c|}
\hline Group & Category of PH & Associated diseases \\
\hline 1 & Pulmonary arterial hypertension (PAH) & $\begin{array}{l}\text { Idiopathic PAH } \\
\text { Heritable } \\
\text { Drug- and toxin-induced } \\
\text { Associated with connective tissue disease, HIV, portal hyperten- } \\
\text { sion, schistosomiasis, chronic hemolytic anemia }\end{array}$ \\
\hline 2 & $\mathrm{PH}$ owing to left heart disease & Systolic dysfunction, diastolic dysfunction, valvular disease \\
\hline 3 & $\mathrm{PH}$ owing to lung diseases or hypoxemia & Chronic obstructive pulmonary disease, interstitial lung disease \\
\hline 4 & Chronic thromboembolic PH (CTEPH) & \\
\hline 5 & $\mathrm{PH}$ with unclear multifactorial mechanisms & Sarcoidosis, lymphangioleiomyomatosis \\
\hline
\end{tabular}

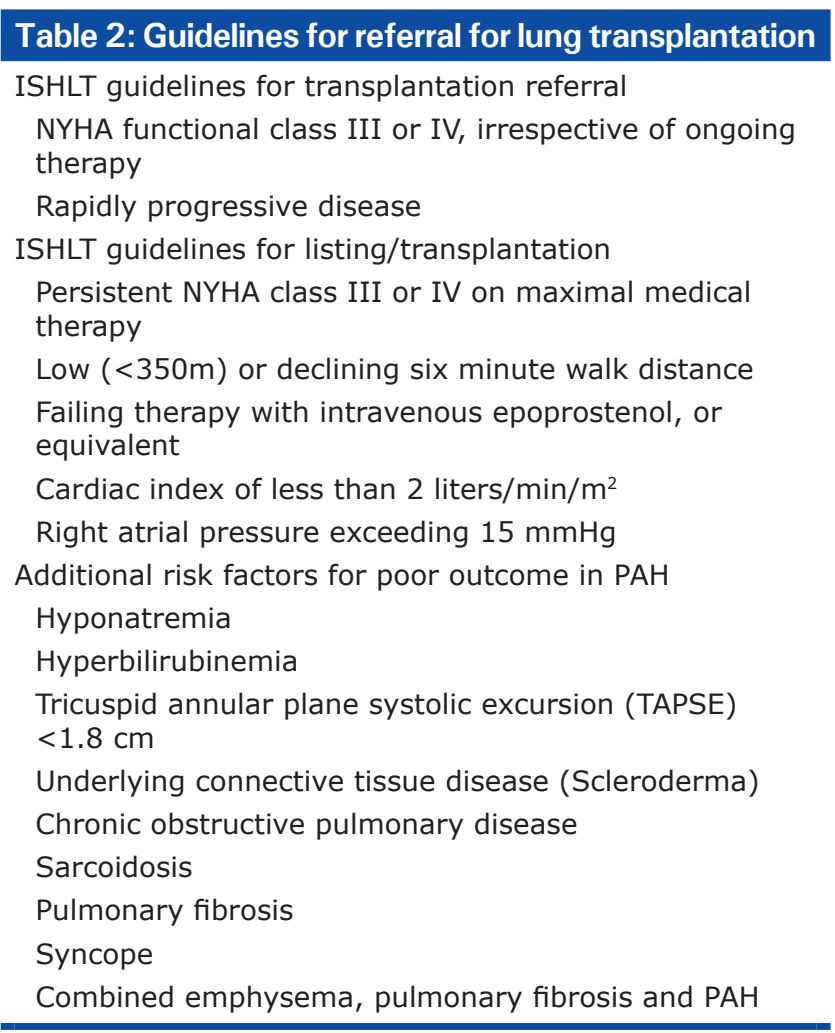

hyperbilirubinemia, echocardiographic evidence of severe right ventricular dysfunction measured by tricuspid annular plane systolic excursion (TAPSE) less than 1.8 $\mathrm{cm}$, and six minute walk distance less than $332 \mathrm{~m} \cdot{ }^{[26-29]}$

Although much progress has been made in treatment of idiopathic pulmonary hypertension (IPAH), additional risk factors to consider in patients with $\mathrm{PAH}$ include history of underlying connective tissue disease (CTD) or other primary lung disease. In a study of patients in the REVEAL registry, patients with scleroderma had higher plasma brain natriuretic peptide levels, lower diffusing capacity for carbon monoxide, and significantly worse one-year survival than patients with IPAH $(82 \%$ in patients with scleroderma vs $86 \%$ in all CTD-PAH vs $93 \%$ in IPAH). ${ }^{[30]}$ Patients with pulmonary hypertension associated with underlying lung diseases such as chronic obstructive pulmonary disease (COPD), pulmonary fibrosis, and sarcoidosis, also are at increased risk of mortality, ${ }^{[31-38]}$ and those with combined emphysema, interstitial lung disease and pulmonary hypertension have a particularly high mortality risk, with only a $60 \%$ one-year survival. ${ }^{[39]}$ Studies have shown variable effects of oral vasodilator therapy in the treatment of PAH associated with lung diseases, presumably due to worsening ventilation/ perfusion mismatch. ${ }^{[40-45]}$ This has been somewhat overcome through the use of inhaled prostacyclins, which may have promise in COPD and interstitial lung diseases. ${ }^{[46,47]}$ Nonetheless, responses to such medications in patients with underlying hypoxemia due to parenchymal lung disease are variable, and the potential for worsening persists. Hence in patients with primary parenchymal disease or CTD, the presence of PAH may indicate a need for expedited transplant evaluation.

Given the difficulty in predicting course of illness in patients with $\mathrm{PAH}$, whether idiopathic or associated with pulmonary parenchymal disease (APAH), it is recommended that patients be referred early to a transplant center for evaluation. Early evaluation allows time for physicians and patients to explore any possible risk factors and devise strategies to overcome them (e.g., obesity and weight loss, deconditioning and pulmonary rehabilitation). There are also circumstances in which patients will not be considered viable candidates for lung transplantation. Contraindications include active cancer, substance abuse, noncompliance with medications, and lack of social support. The consensus statement on lung transplantation candidacy was last published 5 years ago, ${ }^{[48]}$ and many would argue that, given our advancements in surgical and medical transplant care, previous contraindications may no longer apply. In addition, criteria for lung transplant candidacy varies significantly among centers, so early evaluation provides an opportunity for opinions at other more aggressive centers if patients are declined at one center. Acknowledging this evolution in practice, it is best to refer patients to the transplant center for preliminary evaluation. In addition, even when patients with PAH are initially too well to be listed for transplant, early evaluation allows for close follow up should the patient's clinical 
condition decline. Typically patients on the waiting list are seen every three to six months for a medical update and to update their LAS. This is especially important in pulmonary hypertension patients as any change in clinical status may place them at need for LAS appeal and expedited transplantation. Finally, if patients are followed at a tertiary referral center, they may benefit from opportunities to enroll in clinical trials for IPAH or APAH.

\section{PREPARATION: EVALUATION, LISTING FOR TRANSPLANTATION, AND IMPACT OF THE LUNG ALLOCATION SCORE}

Full lung transplant evaluation involves a detailed process to best determine the nature and trajectory of a potential candidate's illness, as well as identify possible risk factors for potential modification. Depending on the center, much of the testing may be done locally, if patients and referring physicians prefer, however visit to the transplant center is usually a several day process. In addition to consultations with transplant pulmonology, transplant surgery, and social services, patients also undergo psychiatric screening and participate in a transplant orientation class. Patients also undergo full laboratory, electrocardiographic, radiologic testing, and cardiac catheterization. In addition, they also must be up to date on vaccines and age-appropriate cancer screening (Table 3).

In 2005, the method in which patients were prioritized for lung transplant underwent a major revision with the development of the lung allocation score (LAS). Prior to this, patients were prioritized on the waiting list by how much time they had accrued on the waiting list. This resulted in many deaths on the waiting list, and compelled physicians to list patients long before they were sick enough to justify the risks of lung transplant. In this era of long waitlist times, when patients' with PAH deteriorated quickly, techniques such as balloon atrial septostomy were utilized by some physicians as a bridge to transplant. ${ }^{[49]}$

To simplify the listing process, reduce time (and deaths) on the waiting list, and help assure that organs would go to those who were in most need, the LAS was developed. [50] The LAS is a scoring system developed from demographic and clinical characteristics, which takes into account waiting list urgency and the probability of post-transplant survival. The score is normalized to range between 0 and 100 , and the sicker a patient is, the higher their score. Patients are placed on the waiting list according to blood type and size, with highest priority going to patients with the highest LAS.
After development of the LAS, the likelihood of transplantation from the waiting list increased for all diagnoses. Deaths on the waiting list decreased for all diagnostic groups except IPAH, which remained unchanged. Under the LAS system, patients with IPAH were less likely to be transplanted than patients with IPF (hazard ratio [HR] 0.53; $\mathrm{P}<0.001$ ) or CF (HR 0.49; $\mathrm{P}<0.001$ ) and more likely to die on the waiting list than patients with COPD (HR 3.09; P<0.001) or CF (HR 1.83, $\mathrm{P}=0.025) \cdot{ }^{[48,51]}$ Critics of the LAS system state that the factors accounted for in the equations are more heavily weighted towards pulmonary function tests, which do not correlate with disease severity in IPAH. In an analysis

\section{Table 3: Pre-transplant evaluation includes consultations and visits to evaluate the candidate's pulmonary disease and risk factors \\ for lung transplantation}

Consultations

- Transplant pulmonologist - candidacy for transplant, risk factor assessment and modification, pretransplant management

- Transplant surgeon - candidacy for transplant, risk factor assessment and modification

- Social services - socioeconomic evaluation, consultation in fundraising if necessary

- Psychiatry - mental health evaluation, addictions screening, medical adherence assessment

Laboratory tests

- Comprehensive metabolic panel, complete blood count, prothrombin and partial thromboplastin time, hypercoagulable screening

- Serologic testing (e.g., human immunodeficiency virus, hepatitis, cytomegalovirus, herpes simplex virus)

- Blood type and screen (x2), screening for antihuman leukocyte antigen panel reactive antibodies

Radiographic tests

- Chest radiograph

- High resolution CT scan

- Ventilation/perfusion scan

- Barium swallow

- Echocardiogram

Cardiovascular tests

- Electrocardiogram

- Echocardiogram

- 6 minute walk test

- Cardiac catheterization

Age-appropriate cancer screening

- Colonoscopy within the last 5 years

- Mammogram/PAP smear within the last year

- Prostate cancer screening within the past year

Education

- Patients and family members attend class

- Online and written materials also provided 
comparing mortality predicted by the LAS system to actual mortality in the REVEAL cohort containing 2967 patients with $\mathrm{PAH}$, two additional variables were independently associated with increased mortality compared to the LAS in multivariable analysis: mean right atrial pressure greater than or equal to $14 \mathrm{mmHg}$ and six minute walk distance less than or equal to $300 \mathrm{~m} \cdot{ }^{[52]}$ Although modification of the LAS system is under discussion, the United Network for Organ Sharing (UNOS)/Organ Procurement and Transplant Network (OPTN) Thoracic Organ Transplantation Committee has adopted criteria for appeal of an LAS in a patient with IPAH (Table 4). A patient with IPAH will be granted a LAS in the $90^{\text {th }}$ percentile of all lung allocation scores when they satisfy all of the following criteria: the patient is deteriorating on optimal medical therapy, right atrial pressure is greater than $15 \mathrm{mmHg}$, and cardiac index is less than $1.8 \mathrm{~L} / \mathrm{min} / \mathrm{m}^{2} .^{[53]}$

The impact of the LAS on patients with IPAH on the waiting list highlights the importance of close follow up while patients are on the waiting list, as they may meet criteria for LAS appeal either at time of listing of later in the course of their disease.

\section{OPERATIVE ISSUES: SINGLE VERSUS DOUBLE LUNG TRANSPLANT}

Most transplant centers now favor double lung transplantation over single lung transplantation (Table 5). Although lung transplantation began with heart-lung transplantation, with technical improvements in the 1990s, single lung transplantation became the procedure of choice for lung transplant when the left ventricular function was intact. Early studies showed that single lung transplantation is quite effective in lowering pulmonary artery pressures and improving right ventricular function.

Early experience at the University of Pittsburgh explored outcomes in single versus double lung transplantation for IPAH. In a retrospective study comparing 37 double lung transplant recipients and 21 single lung transplant recipients transplanted between 1989-1996, one-month, one-year, and four-year survival was comparable between groups. As expected, time on cardiopulmonary bypass was significantly shorter in the single lung recipients. Mean pulmonary artery pressures were significantly lower in the double lung transplant recipients at 1 hour, 12 hours, and 24 hours post-transplant $(\mathrm{P}<0.02)$. While there was a slightly lower incidence of postoperative diffuse alveolar damage in the single lung recipients ( $43 \%$ versus $51 \%$ in double lung recipients), there was a trend toward slightly higher incidence of obliterative bronchiolitis among single lung transplant recipients $(9 / 21,42.9 \%)$ than double lung transplant recipients
$(9 / 37,24.3 \%, P=0.14) .{ }^{[54]}$ In an earlier study, Bando and colleagues noted less improvement in pulmonary artery pressures and increased graft-related mortality in singlelung transplant recipients compared with double lung and heart-lung recipients. ${ }^{[5]}$ In another study comparing single lung transplant recipients with and without pulmonary hypertension, Bando and colleagues found that preoperative pulmonary hypertension was associated with significantly lower one-year survival (53\% versus $72 \%$; $\mathrm{P}<0.05$ ) and New York Heart Association functional class $(\mathrm{P}<0.05){ }^{[56]}$

At Johns Hopkins, Conte and colleagues reviewed the outcomes of all single and double lung transplants performed for IPAH or PAH associated with CTD or primary lung disease. In their review, patients with primary (idiopathic) PAH who received a double lung transplant had better survival than those who received a single lung transplant. ${ }^{[57]}$ Among patients with CTD-

Table 4: Criteria for LAS appeal in lung transplant candidates with IPAH

A patient will be granted a LAS in the $90^{\text {th }}$ percentile if they satisfy all of the following criteria:

1. Patient deteriorating on optimal medical therapy

2. Right atrial pressure greater than $15 \mathrm{mmHg}$

3. Cardiac index less than $1.8 \mathrm{~L} / \mathrm{min} / \mathrm{m}^{2}$

Table 5: Comparison of single, double, and heart lung transplantation

Single lung transplantation

+ Shortest time under anesthesia (may be advantageous in older patients or patients with comorbidities)

+ In cases of PGD, native lung may help sustain patient through early graft dysfunction

+ Allows a greater distribution of scarce resources (two patients can be transplanted from one donor)

- Native lung, if colonized, may be a nidus of infection

- Post-transplant monitoring with pulmonary function testing can be more difficult in patients with airway obstruction

Double lung transplantation

+ Increased survival shown in several diagnostic groups (e.g., COPD, PAH)

+ Postoperative monitoring is often easier to interpret as data are not confounded by native lung function

- Longer operative time may expose patients to increased operative risk

Heart lung transplantation

+ May be the only option in patients with severe RV or LV dysfunction

- Increased mortality

- Extremely scarce resource and often long waiting times for transplant 
associated PAH and APAH (secondary PAH), there was a trend towards improved survival in double lung transplant when the mean pulmonary artery pressure was greater than $40 \mathrm{mmHg} \cdot{ }^{[57]}$ Although single lung transplantation is feasible, ${ }^{\left[{ }^{[8-60]}\right.}$ based on these findings and clinical experience, the majority of centers now favor double lung transplantation for $\mathrm{PAH}$.

Improvement in surgical techniques with double lung transplantation as well as the ability of the right ventricle to recover postoperatively have rendered heart-lung transplantation much less common. In fact, most centers try to avoid heart-lung transplantation when possible, due to increased mortality as well as scarcity of organs. In the most recent analysis of the International Society of Heart Lung Transplantation (ISHLT) registry, median survival in heart-lung transplantation for IPAH was 3.8 years. ${ }^{[7]}$ However, when a patient's disease progresses to the point to right ventricular failure requiring inotropic support, they may require heart-lung transplantation rather than double lung alone. Right ventricular function, therefore, helps determine the window for lung transplantation in PAH.

\section{OUTCOMES: PHYSIOLOGIC IMPROVEMENTS AND SURVIVAL POST LUNG TRANSPLANT}

Immediate peri- and post-operative care in patients transplanted for PAH requires close monitoring and often may require temporary inotropic, vasopressor, and inhaled nitric oxide support. While patients no longer require their pulmonary hypertensive medications, they may require some support of the right ventricle as it recovers. In addition, patients should be monitored closely for the development of primary graft dysfunction in the first 72 hours. Given the complexities of peri-operative management in patients transplanted for $\mathrm{PAH}$, it is recommended that they are managed at a higher volume center with experience in this disease.

The response of the right ventricle to lung transplantation is immediate and remarkable (Fig. 3). Patients are often admitted for surgery on combination vasodilator therapy, only to be completely off pulmonary hypertensive medications with dramatic improvement in pulmonary artery pressures. These improvements are evident in the operating room, as described in a prospective study of intraoperative TEE data: the mean pulmonary artery pressure in those with severe pulmonary hypertension decreased from $76 \pm 14 \mathrm{mmHg}$ to $31 \pm 11 \mathrm{mmHg}(\mathrm{P}<0.05)$ immediately after lung transplantation. ${ }^{[61]}$ In another study looking at hemodynamic data in seven single lung transplant recipients just beyond the immediate postoperative period into the early postoperative period (mean 13 weeks post transplant), mean pulmonary artery pressures decreased from $64 \pm 18 \mathrm{mmHg}$ to $18 \pm 5$ $\mathrm{mmHg}(\mathrm{P}=0.001)$, and pulmonary vascular resistance index decreased from $1924 \pm 663$ dyne sec cm-9 to $233 \pm 73$ dyne sec $\mathrm{cm}-9(\mathrm{P}=0.001){ }^{[60]}$ In a retrospective review of 100 consecutive patients transplanted for idiopathic pulmonary hypertension or pulmonary hypertension secondary to congenital heart disease, reductions in mean pulmonary artery pressures (from $65.9 \pm 13.1 \mathrm{mmHg}$ pre-transplant to $21.9 \pm 5.9 \mathrm{mmHg}$ $(\mathrm{P}<0.001)$ and pulmonary vascular resistance $(18.8 \pm 8.0$ Woods Units pre-transplant to $2.1 \pm 0.9$ Woods Units posttransplant, $\mathrm{P}<0.001$ ) were seen at 24 hours and sustained at 1 year later, and improvement in right ventricular ejection fraction was notable at one year $(26.8 \pm 12.6 \%$ pre-transplant to $56.6 \pm 8.8 \%$ at 1 year, $\mathrm{P}<0.001)$. ${ }^{[62]}$ These results were seen in both single and double lung transplant recipients.

Lung transplantation provides an opportunity for patients to extend their lives as well as improve quality of life. According to the most recent ISHLT registry data, overall median survival for all lung transplant recipients transplanted between January 1994 and June 2008 was 5.3 years, and among those who survive at least 1 year, median survival was 7.5 years. ${ }^{[7]}$ When analyzed by eras in transplantation, overall median survival has significantly improved. Patients transplanted from 2000 through June 2007 have a median survival of 5.7 years, compared with 4.7 and 4.2 years in patients transplanted from 1998 to 1994 , and 1995 to 1999 , respectively. ${ }^{[7]}$

Patients with IPAH have a greater short-term risk after transplant, but also a better chance of long term survival. Patients with PAH have the lowest 3-month and 1-year survival rate $(76 \%$ and $71.1 \%$, respectively), when compared to patients with IPF (85\%, 74.1\%), CF (90\%, $82.6 \%)$, and COPD (91\%, 82.4\%), see Table $6 \mathrm{~A}) \cdot{ }^{[7]}$ In fact, in multivariable analysis, a diagnosis of IPAH was the greatest categorical risk factor for one-year mortality (relative risk [RR] 2.19, 95\% confidence interval [95\%CI] 1.63-2.95, $\mathrm{P}<0.0001) .{ }^{[7]}$ However, when lung transplant recipients with IPAH live for at least one year, they have improved long-term survival compared to patients with other underlying lung diseases. Accounting for risk of early mortality by conditioning survival on living one year, patients with IPAH had a lower risk of 5-year mortality (RR 0.51, P=0.0032) and significantly improved longterm survival (median survival 9.3 years) compared with patients with COPD (6.6 years, $\mathrm{P}=0.01$ ) and IPF (6.7 years, $\mathrm{P}<0.0001$ ), Table 6B). ${ }^{[7]}$

In lung transplant recipients who die within the first year, the most common causes of death are non-CMV infections 


\begin{tabular}{|c|c|c|c|c|}
\hline Year & $\begin{array}{c}\text { IPAH } \\
\mathrm{N}=1,065\end{array}$ & $\begin{array}{c}\text { COPD } \\
\mathrm{N}=\mathbf{8}, \mathbf{8 1 2}\end{array}$ & $\begin{array}{c}\text { CF } \\
N=3,746\end{array}$ & $\begin{array}{c}\text { IPF } \\
N=4,695\end{array}$ \\
\hline 1 & 71.1 & 82.4 & 82.6 & 74.1 \\
\hline 3 & 60.3 & 65.3 & 67.5 & 58.5 \\
\hline 5 & 51.7 & 50.8 & 57.4 & 45.9 \\
\hline 7 & 44.5 & 38.5 & 50.0 & 35.4 \\
\hline 10 & 32.4 & 22.9 & 39.6 & 22.3 \\
\hline
\end{tabular}

\begin{tabular}{|c|c|c|c|c|}
\hline Year & $\begin{array}{c}\text { IPAH } \\
\mathbf{N}=674\end{array}$ & $\begin{array}{c}\text { COPD } \\
N=6,649\end{array}$ & $\begin{array}{c}C F \\
N=2,779\end{array}$ & $\begin{array}{c}\text { IPF } \\
\mathrm{N}=3,108\end{array}$ \\
\hline 1 & 100 & 100 & 100 & 100 \\
\hline 3 & 84.8 & 79.2 & 81.6 & 78.9 \\
\hline 5 & 72.7 & 61.5 & 69.4 & 61.9 \\
\hline 7 & 62.5 & 46.7 & 60.5 & 47.7 \\
\hline 10 & 45.5 & 27.8 & 47.9 & 30.1 \\
\hline
\end{tabular}

and graft failure. ${ }^{[7]}$ Within the early post-operative period, primary graft dysfunction (PGD) is a significant concern in patients with IPAH (as well as in other patients with increased pulmonary arterial pressures in general), and is associated with increased risk of death. ${ }^{[63,64]} \mathrm{PGD}$ is defined as lung injury occurring within the first 72 hours post-transplant, and is considered grade 2-3 when the $\mathrm{PaO} 2 / \mathrm{FiO} 2$ ratio is less than 300 and bilateral infiltrates are present on chest radiograph. ${ }^{[65]}$ While the exact pathogenesis is unknown, pulmonary hypertension has been repeatedly associated with increased risk of PGD, and researchers hypothesize that increased shear stress associated with elevated pulmonary artery pressures during reperfusion may play a role. ${ }^{[64,66-68]}$ Several studies have identified a diagnosis of IPAH as a risk factor for developing PGD. Others have identified elevated pulmonary artery pressures as a risk factor for developing PGD in non-IPAH patients. ${ }^{[68,69]}$ The difficulty with many of these studies, however, is that IPAH and pulmonary artery pressures cannot be completely isolated from other risk factors for PGD, namely use of cardiopulmonary bypass and blood products.
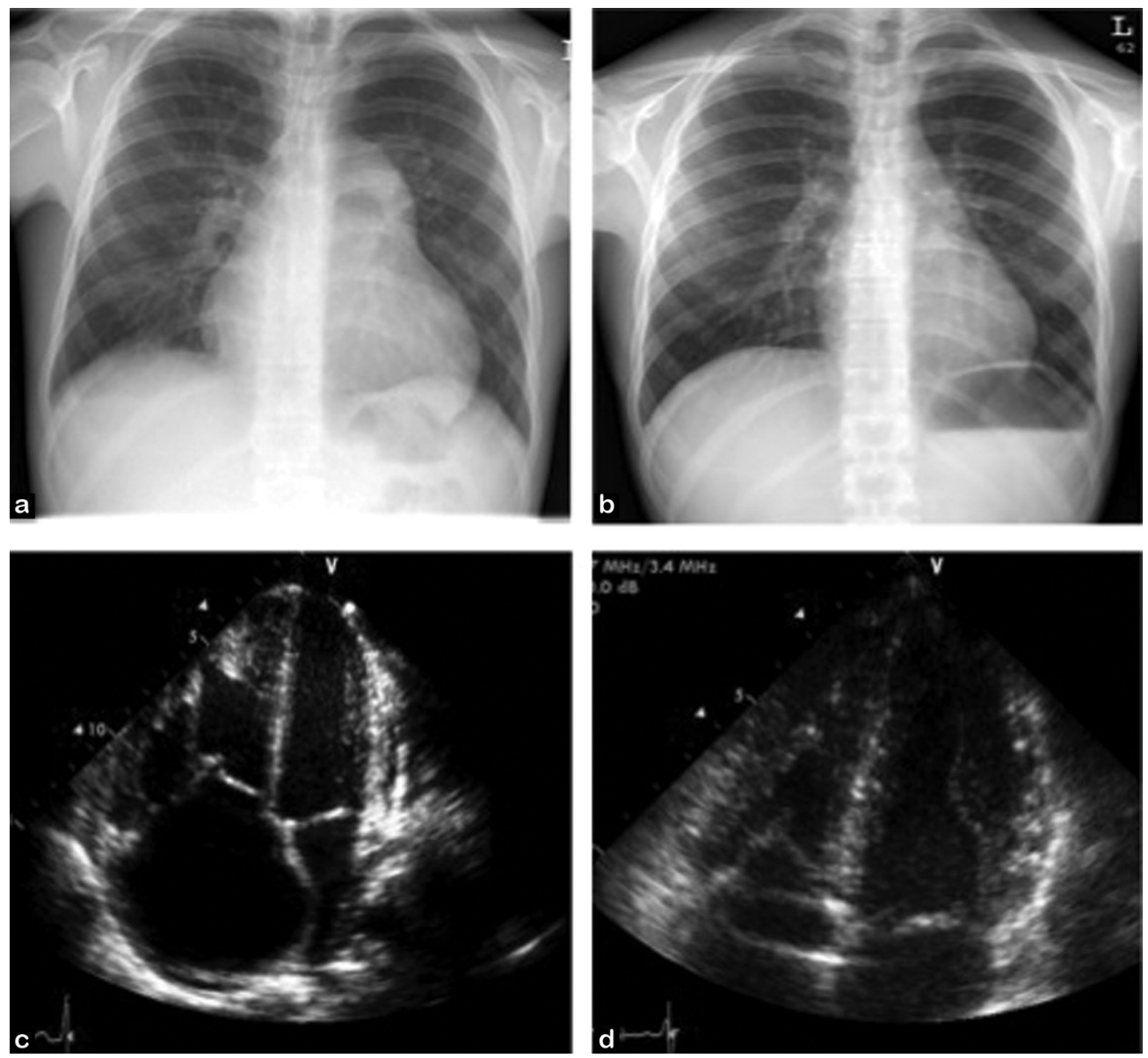

Figure 3: Double lung transplantation is an effective treatment for PAH. Chest radiographs (a) pre- and (b) post-double lung transplant demonstrate radiographic resolution of enlarged pulmonary arteries and right ventricular remodeling post transplant. Echocardiographic images (c) pre- and (d) post-transplant demonstrate resolution of right atrial enlargement and septal bowing seen in severe PAH. 
While the ISHLT data seem to indicate that the diagnosis of IPAH is a risk factor for one-year survival post transplant, it is quite possible that at high-volume centers that specialize in transplant for IPAH, survival is better than ISHLT data. A recent study showed that in general, high-volume transplant centers are associated overall improved five-year survival. ${ }^{[70]}$ In a retrospective study of patients with PAH at the University of Pittsburgh, which has performed over 60 lung transplants per year over the past 7 years, one-year survival in cohort of 30 patients transplanted between 1994-2006 was 86\%, compared to $66 \%$ in the comparable ISHLT cohort, and 58\% in IPAH patients transplanted at the University of Pittsburgh from 1982 to $1993 .{ }^{[71]}$ The authors attributed their improved outcomes to improvements in donor and recipient surgical techniques as well as improvements in postoperative medical management of transplant recipients ${ }^{[71]}$ Similarly, a retrospective study of 220 patients transplanted between 1986 and 2008 at Marie-Lannelongue Hospital in Paris reported a 79\% one-year survival among double lung transplant recipients in patients with IPAH. ${ }^{[72]}$ These studies suggest potential benefit to performing transplants for PAH at experienced high-volume centers.

Most lung transplant recipients enjoy improved functional status post transplantation. In a single center survey comparing 54 lung transplant recipients to 44 transplant candidates, recipients reported higher levels of happiness with their life and health as well as improved functional status. ${ }^{[73]}$ In a cross-sectional analysis of the functional status of lung transplant recipients in the ISHLT dataset, over $80 \%$ of survivors reported no limitations in activities, and less than $3 \%$ reported need for full assistance with activities. ${ }^{[7]}$ In a study of US recipients using Karnofsky score for adult recipients, over $80 \%$ of survivors reported the ability to function at $80 \%$ their functional status or greater at years 2 and $3 \cdot{ }^{[7]}$

Although survival, functionality, and quality of life are enhanced post transplant, recipients are at increased risk of bronchiolitis obliterans syndrome (BOS) and other co-morbidities commonly seen with corticosteroids and chronic immunosuppression. The most common conditions include hypertension, chronic kidney disease, hyperlipidemia, and diabetes. According to ISHLT data, among 1-year survivors, $52.5 \%$ have hypertension, $26.3 \%$ have diabetes, $24.4 \%$ have kidney disease $(1.7 \%$ on dialysis or requiring renal transplant), $24.2 \%$ have hyperlipidemia, and $9.6 \%$ have BOS. Among 5-year survivors, $84.4 \%$ have hypertension, $24.7 \%$ have kidney disease (3.3\% on dialysis or requiring renal transplant), $56.5 \%$ have hyperlipidemia, $38 \%$ have diabetes, and $36.9 \%$ have BOS. ${ }^{[7]}$ It is important for patients to realize that immunosuppression-related medical comorbidities of lung transplant are common, and that lung transplantation, therefore, provides a treatment for their lung disease that requires life-long management. Patients are often told that lung transplant provides a treatment but not a cure, meaning that patients will exchange their chronic lung disease for another medical condition that requires active therapy for the rest of their lives. Nonetheless, when a patient is willing to accept this possibility, and provided there are no major complications, lung transplantation provides a means to significantly improve one's quality of life.

\section{CONCLUSIONS}

Despite significant medical advancements, PAH remains a chronic, terminal disease. For patients who are refractory to medical therapy, lung transplantation remains the only therapeutic option. It is important to refer patients early to a transplant center, as the center can follow patients through their pre-transplant course of disease and better decide when to list for transplantation. Communication between the referring physician and transplant team is key in co-managing patients prior to and after transplantation. Given the technical challenges, it may be beneficial for lung transplantation for PAH to be performed in an experienced center. In the majority of cases, lung transplantation provides patients the chance to improve their quality and duration of life.

\section{REFERENCES}

1. Dresdale DT, Schultz M, Michtom RJ. Primary pulmonary hypertension. I. Clinical and hemodynamic study. Am J Med 1951;11:686-705.

2. D'Alonzo GE, Barst RJ, Ayres SM, Bergofsky EH, Brundage BH, Detre KM, et al. Survival in patients with primary pulmonary hypertension. Results from a national prospective registry. Ann Intern Med 1991;115:343-9.

3. Reitz BA. The first successful combined heart-lung transplantation. J Thorac Cardiovasc Surg 2011;141:867-9.

4. Cooper JD, Pearson FG, Patterson GA, Todd TR, Ginsberg RJ, Goldberg $\mathrm{M}$, et al. Technique of successful lung transplantation in humans. J Thorac Cardiovasc Surg 1987;93:173-81

5. Patterson GA, Cooper JD, Goldman B, Weisel RD, Pearson FG, Waters PF, et al. Technique of successful clinical double-lung transplantation. Ann Thorac Surg 1988;45:626-33

6. Kaiser LR, Pasque MK, Trulock EP, Low DE, Dresler CM, Cooper JD. Bilateral sequential lung transplantation: The procedure of choice for double-lung replacement. Ann Thorac Surg 1991;52:438-45; discussion 445-6.

7. Christie JD, Edwards LB, Kucheryavaya AY, Aurora P, Dobbels F, Kirk $\mathrm{R}$, et al. The registry of the International Society for Heart and Lung Transplantation: Twenty-seventh official adult lung and heart-lung transplant report--2010. J Heart Lung Transplant 2010;29:1104-18

8. Rubin LJ, Groves BM, Reeves JT, Frosolono M, Handel F, Cato AE. Prostacyclin-induced acute pulmonary vasodilation in primary pulmonary hypertension. Circulation 1982;66:334-8.

9. Higenbottam T, Wheeldon D, Wells F, Wallwork J. Long-term treatment of primary pulmonary hypertension with continuous intravenous epoprostenol (prostacyclin). Lancet 1984;1:1046-7.

10. Rubin LJ, Mendoza J, Hood M, McGoon M, Barst R, Williams WB, et al. Treatment of primary pulmonary hypertension with continuous intravenous prostacyclin (epoprostenol). Results of a randomized trial. Ann Intern Med 1990;112:485-91.

11. Barst RJ, Rubin LJ, Long WA, McGoon MD, Rich S, Badesch DB, et al. A comparison of continuous intravenous epoprostenol (prostacyclin) with 
conventional therapy for primary pulmonary hypertension. The primary pulmonary hypertension study group. N Engl J Med 1996;334:296-302.

12. Sitbon O, Humbert M, Nunes H, Parent F, Garcia G, Herve P, et al. Long-term intravenous epoprostenol infusion in primary pulmonary hypertension: Prognostic factors and survival. J Am Coll Cardiol 2002;40:780-8.

13. Simonneau G, Barst RJ, Galie N, Naeije R, Rich S, Bourge RC, et al. Continuous subcutaneous infusion of treprostinil, a prostacyclin analogue, in patients with pulmonary arterial hypertension: A doubleblind, randomized, placebo-controlled trial. Am J Respir Crit Care Med 2002;165:800-4.

14. Hoeper MM, Schwarze M, Ehlerding S, Adler-Schuermeyer A, Spiekerkoetter E, Niedermeyer J, et al. Long-term treatment of primary pulmonary hypertension with aerosolized iloprost, a prostacyclin analogue. N Engl J Med 2000;342:1866-70.

15. Machherndl S, Kneussl M, Baumgartner H, Schneider B, Petkov V, Schenk $\mathrm{P}$, et al. Long-term treatment of pulmonary hypertension with aerosolized iloprost. Eur Respir J 2001;17:8-13.

16. Krug S, Sablotzki A, Hammerschmidt S, Wirtz H, Seyfarth HJ. Inhaled iloprost for the control of pulmonary hypertension. Vasc Health Risk Manag 2009;5:465-74.

17. Rubin LJ, Badesch DB, Barst RJ, Galie N, Black CM, Keogh A, et al. Bosentan therapy for pulmonary arterial hypertension. N Engl J Med 2002;346:896-903.

18. Jacobs A, Preston IR, Gomberg-Maitland M. Endothelin receptor antagonism in pulmonary arterial hypertension--a role for selective $\mathrm{ET}_{\mathrm{A}}$ inhibition? Curr Med Res Opin 2006;22:2567-74

19. Galie N, Ghofrani HA, Torbicki A, Barst RJ, Rubin LJ, Badesch D, et al. Sildenafil citrate therapy for pulmonary arterial hypertension. N Engl J Med 2005;353:2148-57.

20. Schermuly RT, Dony E, Ghofrani HA, Pullamsetti S, Savai R, Roth M, et al. Reversal of experimental pulmonary hypertension by PDGF inhibition. J Clin Invest 2005;115:2811-21.

21. Mittendorf J, Weigand S, Alonso-Alija C, Bischoff E, Feurer A, Gerisch M, et al. Discovery of riociguat (BAY 63-2521): A potent, oral stimulator of soluble guanylate cyclase for the treatment of pulmonary hypertension. ChemMedChem 2009;4:853-65.

22. Galie N, Manes A, Negro L, Palazzini M, Bacchi-Reggiani ML, Branzi A. A meta-analysis of ran domized controlled trials in pulmonary arterial hypertension. Eur Heart J 2009;30:394-403.

23. McLaughlin VV, Archer SL, Badesch DB, Barst RJ, Farber HW, Lindner JR, et al. ACCF/AHA 2009 expert consensus document on pulmonary hypertension a report of the American College of Cardiology Foundation task force on expert consensus documents and the American Heart Association. J Am Coll Cardiol 2009;53:1573-619.

24. Simonneau G, Robbins IM, Beghetti M, Channick RN, Delcroix M, Denton $\mathrm{CP}$, et al. Updated clinical classification of pulmonary hypertension. J Am Coll Cardiol 2009;54:S43-54.

25. Simonneau G, Galie N, Rubin LJ, Langleben D, Seeger W, Domenighetti G, et al. Clinical classification of pulmonary hypertension. J Am Coll Cardiol 2004;43:5S-12S.

26. Forfia PR, Mathai SC, Fisher MR, Housten-Harris T, Hemnes AR, Champion HC, et al. Hyponatremia predicts right heart failure and poor survival in pulmonary arterial hypertension. Am J Respir Crit Care Med 2008;177:1364-9.

27. Takeda Y, Takeda Y, Tomimoto S, Tani T, Narita H, Kimura G. Bilirubin as a prognostic marker in patients with pulmonary arterial hypertension. BMC Pulm Med 2010;10:22.

28. Forfia PR, Fisher MR, Mathai SC, Housten-Harris T, Hemnes AR, Borlaug BA, et al. Tricuspid annular displacement predicts survival in pulmonary hypertension. Am J Respir Crit Care Med 2006;174:1034-41.

29. Miyamoto S, Nagaya N, Satoh T, Kyotani S, Sakamaki F, Fujita M, et al. Clinical correlates and prognostic significance of six-minute walk test in patients with primary pulmonary hypertension. Comparison with cardiopulmonary exercise testing. Am J Respir Crit Care Med 2000;161:487-92.

30. Chung L, Liu J, Parsons L, Hassoun PM, McGoon M, Badesch DB, et al. Characterization of connective tissue disease-associated pulmonary arterial hypertension from reveal: Identifying systemic sclerosis as a unique phenotype. Chest 2010;138:1383-94.

31. Minai OA, Chaouat A, Adnot S. Pulmonary hypertension in copd: Epidemiology, significance, and management: Pulmonary vascular disease: The global perspective. Chest 2010;137:39S-51S.

32. Oswald-Mammosser M, Weitzenblum E, Quoix E, Moser G, Chaouat A, Charpentier $\mathrm{C}$, et al. Prognostic factors in COPD patients receiving longterm oxygen therapy. Importance of pulmonary artery pressure. Chest
1995;107:1193-8.

33. Chaouat A, Bugnet AS, Kadaoui N, Schott R, Enache I, Ducolone A, et al. Severe pulmonary hypertension and chronic obstructive pulmonary disease. Am J Respir Crit Care Med 2005;172:189-94.

34. Weitzenblum E, Chaouat A, Canuet M, Kessler R. Pulmonary hypertension in chronic obstructive pulmonary disease and interstitial lung diseases. Semin Respir Crit Care Med 2009;30:458-70.

35. Lettieri CJ, Nathan SD, Barnett SD, Ahmad S, Shorr AF. Prevalence and outcomes of pulmonary arterial hypertension in advanced idiopathic pulmonary fibrosis. Chest 2006;129:746-52.

36. Hamada K, Nagai S, Tanaka S, Handa T, Shigematsu M, Nagao T, et al. Significance of pulmonary arterial pressure and diffusion capacity of the lung as prognosticator in patients with idiopathic pulmonary fibrosis. Chest 2007;131:650-6.

37. Palmero V, Sulica R. Sarcoidosis-associated pulmonary hypertension: Assessment and management. Semin Respir Crit Care Med 2010;31: 494-500.

38. Heresi GA, Dweik RA. Sarcoidosis-associated pulmonary hypertension. One size does not fit all. Chest 2009;135:1410-2.

39. Cottin V, Le Pavec J, Prevot G, Mal H, Humbert M, Simonneau G, et al. Pulmonary hypertension in patients with combined pulmonary fibrosis and emphysema syndrome. Eur Respir J 2010;35:105-11.

40. Blanco I, Gimeno E, Munoz PA, Pizarro S, Gistau C, Rodriguez-Roisin R, et al. Hemodynamic and gas exchange effects of sildenafil in patients with chronic obstructive pulmonary disease and pulmonary hypertension. Am J Respir Crit Care Med 2010;181:270-8.

41. Stolz D, Rasch H, Linka A, Di Valentino M, Meyer A, Brutsche M, et al. A randomised, controlled trial of bosentan in severe COPD. Eur Respir J 2008;32:619-28.

42. Ghofrani HA, Wiedemann R, Rose F, Schermuly RT, Olschewski H, Weissmann N, et al. Sildenafil for treatment of lung fibrosis and pulmonary hypertension: A randomised controlled trial. Lancet. 2002;360:895-900.

43. Jackson RM, Glassberg MK, Ramos CF, Bejarano PA, Butrous G, Gomez-Marin O. Sildenafil therapy and exercise tolerance in idiopathic pulmonary fibrosis. Lung 2010;188:115-23.

44. Barnett CF, Bonura EJ, Nathan SD, Ahmad S, Shlobin OA, Osei K, et al. Treatment of sarcoidosis-associated pulmonary hypertension. A twocenter experience. Chest 2009;135:1455-61.

45. Zisman DA, Schwarz M, Anstrom KJ, Collard HR, Flaherty KR, Hunninghake GW. A controlled trial of sildenafil in advanced idiopathic pulmonary fibrosis. N Engl J Med 2010;363:620-8.

46. Dernaika TA, Beavin M, Kinasewitz GT. Iloprost improves gas exchange and exercise tolerance in patients with pulmonary hypertension and chronic obstructive pulmonary disease. Respiration 2010;79:377-82.

47. Tissieres P, Nicod L, Barazzone-Argiroffo C, Rimensberger PC, Beghetti M. Aerosolized iloprost as a bridge to lung transplantation in a patient with cystic fibrosis and pulmonary hypertension. Ann Thorac Surg 2004;78:e48-50.

48. Orens JB, Estenne M, Arcasoy S, Conte JV, Corris P, Egan JJ, et al. International guidelines for the selection of lung transplant candidates: 2006 update--a consensus report from the pulmonary scientific council of the international society for heart and lung transplantation. J Heart Lung Transplant 2006;25:745-55.

49. Rothman A, Sklansky MS, Lucas VW, Kashani IA, Shaughnessy RD, Channick RN, et al. Atrial septostomy as a bridge to lung transplantation in patients with severe pulmonary hypertension. Am J Cardiol 1999;84:682-6.

50. Davis SQ, Garrity ER Jr. Organ allocation in lung transplant. Chest 2007;132:1646-51.

51. Chen H, Shiboski SC, Golden JA, Gould MK, Hays SR, Hoopes CW, et al. Impact of the lung allocation score on lung transplantation for pulmonary arterial hypertension. Am J Respir Crit Care Med 2009;180:468-74.

52. Benza RL, Miller DP, Gomberg-Maitland M, Frantz RP, Foreman AJ, Coffey CS, et al. Predicting survival in pulmonary arterial hypertension: Insights from the registry to evaluate early and long-term pulmonary arterial hypertension disease management (REVEAL). Circulation 2010;122: 164-72.

53. Chan KM. Idiopathic pulmonary arterial hypertension and equity of donor lung allocation in the era of the lung allocation score: Are we there yet? Am J Respir Crit Care Med 2009;180:385-7.

54. Gammie JS, Keenan RJ, Pham SM, McGrath MF, Hattler BG, Khoshbin E, et al. Single- versus double-lung transplantation for pulmonary hypertension. J Thorac Cardiovasc Surg 1998;115:397-402.

55. Bando K, Armitage JM, Paradis IL, Keenan RJ, Hardesty RL, Konishi $\mathrm{H}$, et al. Indications for and results of single, bilateral, and heart-lung 
transplantation for pulmonary hypertension. J Thorac Cardiovasc Surg 1994;108:1056-65.

56. Bando K, Keenan RJ, Paradis IL, Konishi H, Komatsu K, Hardesty RL, et al. Impact of pulmonary hypertension on outcome after single-lung transplantation. Ann Thorac Surg 1994;58:1336-42.

57. Conte JV, Borja MJ, Patel CB, Yang SC, Jhaveri RM, Orens JB. Lung transplantation for primary and secondary pulmonary hypertension. Ann Thorac Surg 2001;72:1673-79; discussion 1679-80.

58. Levine SM, Gibbons WJ, Bryan CL, Walling AD, Brown RW, Bailey SR, et al. Single lung transplantation for primary pulmonary hypertension. Chest 1990;98:1107-15.

59. Girard C, Mornex JF, Gamondes JP, Griffith N, Clerc J. Single lung transplantation for primary pulmonary hypertension without cardiopulmonary bypass. Chest 1992;102:967-8.

60. Pasque MK, Trulock EP, Cooper JD, Triantafillou AN, Huddleston $\mathrm{CB}$, Rosenbloom $\mathrm{M}$, et al. Single lung transplantation for pulmonary hypertension. Single institution experience in 34 patients. Circulation 1995;92:2252-8.

61. Katz WE, Gasior TA, Quinlan JJ, Lazar JM, Firestone L, Griffith BP, et al. Immediate effects of lung transplantation on right ventricular morphology and function in patients with variable degrees of pulmonary hypertension. J Am Coll Cardiol 1996;27:384-91.

62. Mendeloff EN, Meyers BF, Sundt TM, Guthrie TJ, Sweet SC, de la Morena $\mathrm{M}$, et al. Lung transplantation for pulmonary vascular disease. Ann Thorac Surg 2002;73:209-17.

63. Thabut G, Vinatier I, Stern JB, Leseche G, Loirat P, Fournier M, et al. Primary graft failure following lung transplantation: Predictive factors of mortality. Chest 2002;121:1876-82.

64. Whitson BA, Nath DS, Johnson AC, Walker AR, Prekker ME, Radosevich $\mathrm{DM}$, et al. Risk factors for primary graft dysfunction after lung transplantation. J Thorac Cardiovasc Surg 2006;131:73-80.

65. Christie JD, Carby M, Bag R, Corris P, Hertz M, Weill D. Report of the ISHLT working group on primary lung graft dysfunction part II: Definition. A consensus statement of the international society for heart and lung transplantation. J Heart Lung Transplant 2005;24:1454-9.

66. Lee J, Kuntz C, Kawut S, Hadjiliadis D, Ahya V, Wille K, et al. 21: Clinica risk factors for the development of primary graft dysfunction. J Heart Lung Transplant 2008;27:S67-8.

67. Christie JD, Kotloff RM, Pochettino A, Arcasoy SM, Rosengard BR, Landis $\mathrm{JR}$, et al. Clinical risk factors for primary graft failure following lung transplantation. Chest 2003;124:1232-41.

68. Kuntz CL, Hadjiliadis D, Ahya VN, Kotloff RM, Pochettino A, Lewis J, et al Risk factors for early primary graft dysfunction after lung transplantation: A registry study. Clin Transplant 2009;23:819-30.

69. Fang A, Studer S, Kawut SM, Ahya VN, Lee J, Wille K, et al. Elevated pulmonary artery pressure is a risk factor for primary graft dysfunction following lung transplantation for idiopathic pulmonary fibrosis. Chest 2011;139:782-7.

70. Thabut G, Christie JD, Kremers WK, Fournier M, Halpern SD. Survival differences following lung transplantation among us transplant centers. JAMA 2010;304:53-60.

71. Toyoda Y, Thacker J, Santos R, Nguyen D, Bhama J, Bermudez C, et al. Long-term outcome of lung and heart-lung transplantation for idiopathic pulmonary arterial hypertension. Ann Thorac Surg 2008;86:1116-22.

72. Fadel E, Mercier O, Mussot S, Leroy-Ladurie F, Cerrina J, Chapelier A, et al. Long-term outcome of double-lung and heart-lung transplantation for pulmonary hypertension: A comparative retrospective study of 219 patients. Eur J Cardiothorac Surg 2010;38:277-84.

73. Gross CR, Savik K, Bolman RM 3rd, Hertz MI. Long-term health status and quality of life outcomes of lung transplant recipients. Chest 1995; 108:1587-93.

Source of Support: Nil, Conflict of Interest: None declared. 